\title{
Broadband Koch Fractal Boundary Printed Slot Antenna for ISM Band Applications
}

\author{
V. V. Reddy \\ Electronics and Communication Engineering Department, KITS, Warangal, India \\ E-mail: vvreddy2005@gmail.com
}

\begin{abstract}
A new broadband radiating slot antenna with fractal shape is modeled, fabricated and experimentally studied. The presented slot antenna is examined for first three iterations. Optimization of iteration factor (IF) and iteration angle (IA) have been done for each iteration order (IO) to enhance the impedance bandwidth significantly. All the antennas are fed with a simple microstrip line. Bandwidth achieved with Antenna $1\left(\mathrm{IO}=1, \mathrm{IF}=0.35\right.$ and $\left.\mathrm{IA}=60^{\circ}\right)$ is $1550 \mathrm{MHz}$ which is five times more than that of the square slot antenna. The performance of the proposed fractal slots is also compared with the rotated slot antenna. The experimental data validates the reported analysis with a close agreement.
\end{abstract}

\section{Introduction}

Recent advancements in the wireless communication systems field require compact size and broadband microstrip antennas [1]. Printed circuit antennas have been thoroughly enquired in the last two decades. Among them slot antennas have played an important role for a variety of radar and satellite communication applications. The broad bandwidth, less radiation from feeding network, good isolation and less interaction via surface waves are the advantages of slot antennas. Detailed description, mathematical modeling and analysis of a microstrip slot antenna have been thoroughly studied [2]. Slot antennas with different shapes such as square [3], circle, ellipse, triangle and E-shape are reported for wide bandwidth. A printed wide-slot microstrip antenna feeding with a microstrip line having a fork-like tuning stub is mentioned for bandwidth improvement [4] and [5]. Bandwidth enhancement is achieved by a rotating the slot in the center of a square [6]. A slot and a monopole antenna printed on a single substrate is suggested for broadband operation [7]. The antenna structure mainly composed of a rectangular slotted patch and a metallic reflector is proposed by Chen et al for wideband operation [8]. A microstrip-fed reconfigurable eccentric annular ring slot antenna with switchable polarization is demonstrated by Sim et al [9]. A two slot antenna for long-term evolution usable on the metal body handsets is studied by Chang et al [10].

Fractal concept is best depicted and yielded by employing an iterative procedure that results to self-similar and self-affine structures. Fractals display space-filling attributes that can be utilized to cut down the classical antenna elements size, such as dipoles and loops, and thus subdue some of the restrictions of small antennas [11]. Fractal patches are studied for multiband or wideband applications [12] and [13]. The operational features of the Koch fractal monopole are analysed and compared with those of other bent wire geometry monopoles having the same wire length and height. It is established that they have less advantages; on the other hand, planar fractal antennas are shown to be more advantageous in terms of radiation characteristics when compared with the conventional patch antennas [14]. Fractal slots with various iteration orders and iteration factors have been proposed by Wen-Ling Chen et al [15] and Y.J.Sung [16]. Yassen et al have suggested a koch fractal snowflake annular ring dual band slot antenna [17]. Fractal based antennas for various wireless applications like Wi-Fi, RFID, UWB are proposed in open literature [18] [22]. Based on the concept of embedded structures, a wideband spidron fractal microstrip antenna is investigated [23]

Here, the authors introduce a microstrip line-fed koch fractal radiating slot antenna for bandwidth enhancement. The analysis is carried out for different IF and IA, Koch fractal slot is used. In this work using fractals the path of the current distribution has been changed. This led to the change of lower edge of the operating frequency. Such a significant change in bandwidth is because of the change in the lower and upper edges of the working frequency band of the wide slot antenna. For a slot antenna and with the rotation of the slot, always the secondary resonant frequency is dominating one. On the other hand, in a fractal slot antenna, with the increase of iteration order the dominant changes are from second resonance frequency to first resonance frequency. The proposed antenna is analyzed for linear polarization. There is a considerable enhancement of impedance bandwidth with this fractal slot antenna when compared with the square slot and rotated slot. FDTD analysis for the first two iterations is presented. The measured data agrees well with the theoretical results. 


\section{Antenna Configuration}

In order to generate two modes with close resonant frequencies to enhance the impedance bandwidth, initially a square slot antenna is introduced. A Koch curve is generated as indicated in Fig. 1.The straight line is divided into three equal sections. The central section is replaced by two lines at an angle (IA). This process is repeated up to IO three to get fractal shapes.

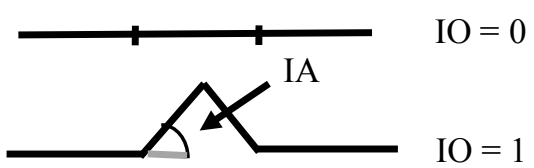

Figure 1. Koch curve generation

The generated Koch curve is characterized by three factors: the construction of fractal by iteration factor (IF), the number of iteration processes by iteration order (IO) and angle of koch curve by iteration angle (IA). The proposed antenna dimensions are given in Fig. 2 with $\mathrm{IO}=2, \mathrm{IF}=0.5$ and $\mathrm{IA}=60^{\circ}$. The printed wide slot is etched on a grounded substrate with a thickness of $1.6 \mathrm{~mm}$ and relative dielectric permittivity of 4.4 .

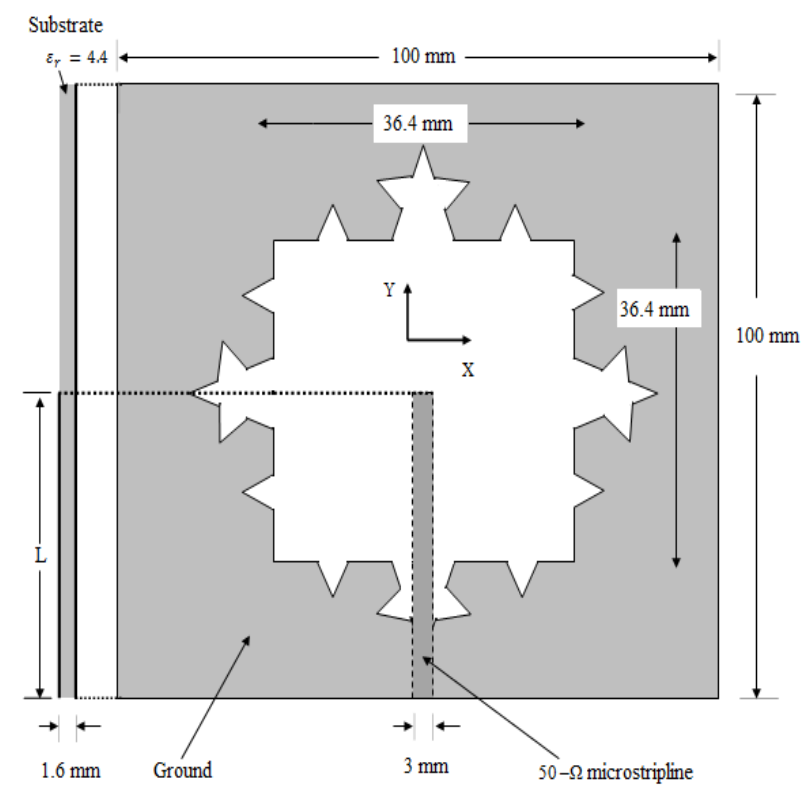

Figure 2. Geometry and dimensions of the proposed microstrip-line-fed printed Fractal-shaped slot antenna $\left(\mathrm{IF}=0.5, \mathrm{IO}=2, \mathrm{IA}=60^{\circ}\right)$.

To stimulate the antenna such that it operates around 2300 $\mathrm{MHz}$, the dimensions of the slot are determined from the expression given below [24]

$$
f=\frac{c}{2 L_{e x t} \sqrt{\varepsilon_{r}}}
$$

Where $\mathrm{c}$ is light speed, $\varepsilon_{r}$ is the effective relative permittivity and $\mathrm{L}_{\text {ext }}$ is the external perimeter of antenna slot structure calculated using the fractal sides length and width. Initially the value of $\mathrm{W}$ is chosen as $36.4 \mathrm{~mm}$. The ground plane size considered as $100 \mathrm{~mm} \times 100 \mathrm{~mm}$. The feeding is a $50-\Omega$ microstrip line of straight length of $L$ printed on other side of substrate. The width of the strip line for square and rotated slot antennas is optimized to $2 \mathrm{~mm}$ to get better reflection coefficient characteristics. The FDTD analysis is also carried out for the proposed antenna [25].

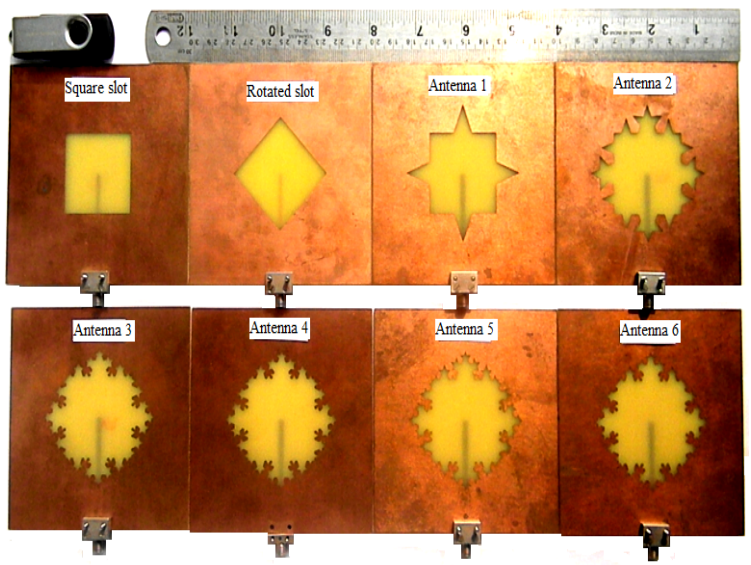

Figure 3. Prototype of fabricated slot antennas.

\section{Results and Discussion}

To observe the performance, all the antennas are fabricated. Fig. 3 shows the prototype of fabricated antennas. All the simulations are carried with the Finite Element method based HFSS software and are presented in Fig. 4.

In order to achieve significant enhancement of bandwidth, optimization of IF is done for the slot antennas. As depicted in the Fig. 6, with the increase of IO and as shown in the Fig. 7, with the change of IF for the same IO 3 there is a change in the calculated bandwidth. 


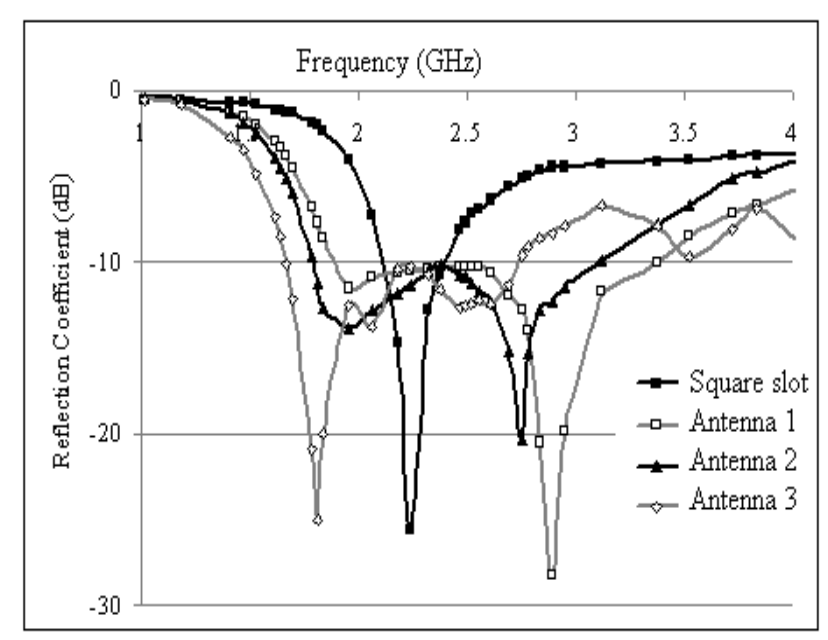

Figure 4. Simulated reflection coefficients of the fractal slot antennas.

The shift of the primary resonant frequency is upward for Antennas 1 and 2, where as for Antenna 3 it is downward in
Figure 6. The reason behind this is with the increase of IO, electrical length of the slot also increases and so lower frequencies become more dominant [19]. The comparison of Antenna 2 measured reflection coefficient with FDTD result is given in Fig. 8. As the number of IO increases, the antenna becomes more compact and the fabrication process becomes a bit difficult. So IO is limited to only three. The reflections coefficients of the entire intended slot antenna are measured with HP 8719A (130MHz - 13.5GHz) Network Analyzer. The radiation patterns are measured in standard anechoic chamber of a defense organization. Electric current distribution of Antenna 3 at 1.8, 3, $4 \mathrm{GHz}$ frequencies is indicated in Fig. 9. Strong current distribution is observed along the fractal boundary at 1.8 and $3 \mathrm{GHz}$ frequencies, whereas at $4 \mathrm{GHz}$ frequency weak current distribution is noticed. The comparison between numerical results and measured data is given in Fig. 8. $\mathrm{E}$ and $\mathrm{H}$ plane patterns of Antenna 3 are measured at four different frequencies as depicted in Fig. 5. Table 1 summarizes the simulated and measured results of the fractal slot antenna.

Table 1: Summarized results of the square slot, rotated slot and fractal slots

\begin{tabular}{|c|c|c|c|c|c|c|c|c|c|}
\hline \multirow{2}{*}{$\begin{array}{c}\text { Antenna } \\
\text { type }\end{array}$} & & & & \multicolumn{2}{|c|}{ Frequency range (GHz) } & \multicolumn{5}{|c|}{ Impedance bandwidth BW } \\
\cline { 5 - 11 } & IO & IF & IA & Simulated & Measured & $\begin{array}{c}\text { Simulated } \\
(\mathrm{MHz})\end{array}$ & $\begin{array}{c}\text { Measured } \\
(\mathrm{MHz})\end{array}$ & $\begin{array}{c}\text { Simulated } \\
(\%)\end{array}$ & $\begin{array}{c}\text { Measured } \\
(\%)\end{array}$ \\
\hline $\begin{array}{c}\text { Square slot } \\
\text { Rotated } \\
\text { slot }\end{array}$ & 0 & 0 & $0^{0}$ & $2.1-2.415$ & $2.120-2.40$ & 315 & 280 & 13.95 & 12.3 \\
\hline Antenna 1 & 1 & 0.35 & $0^{0}$ & $2.12-3.405$ & $2.181-3.378$ & 1285 & 1197 & 46.51 & $43.1 \%$ \\
\hline Antenna 2 & 2 & 0.5 & $60^{0}$ & $1.825-3.375$ & $1.880-3.40$ & 1550 & 1520 & 59.6 & 57.5 \\
\hline Antenna 3 & 3 & 0.45 & $60^{0}$ & $1.665-2.825$ & $1.668-2.75$ & 1160 & 1082 & 51.6 & 48.98 \\
\hline Antenna 4 & 3 & 0.5 & $63^{0}$ & $1.65-2.805$ & $1.65-2.82$ & 1155 & 1170 & 51.8 & 52.3 \\
\hline Antenna 5 & 3 & 0.55 & $66^{0}$ & $1.635-2.795$ & $1.642-2.78$ & 1160 & 1138 & 52.3 & 51.4 \\
\hline Antenna 6 & 3 & 0.6 & $70^{0}$ & $1.63-2.77$ & $1.6395-2.76$ & 1140 & 1120 & 51.8 & 50.9 \\
\hline
\end{tabular}

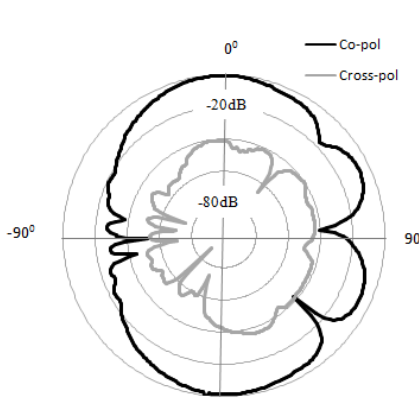

E

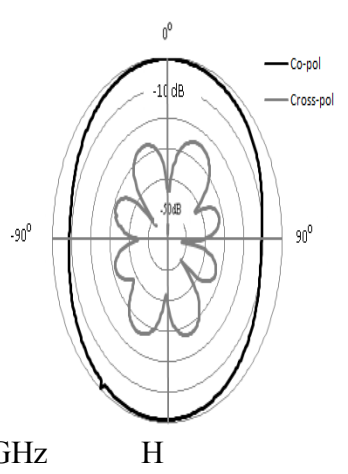

$1.8 \mathrm{GHz}$

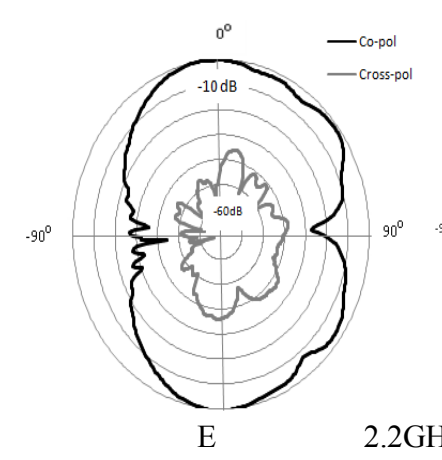

E

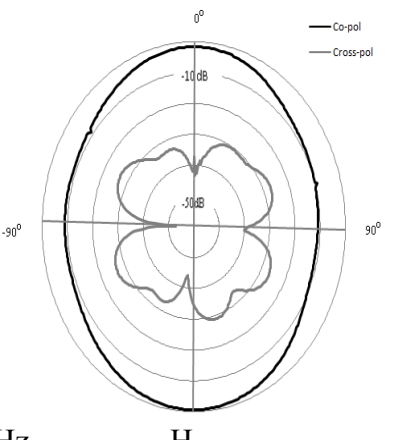

$\mathrm{H}$ 


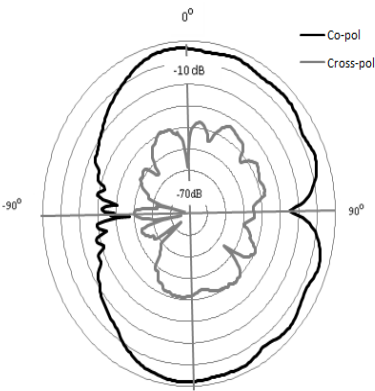

E

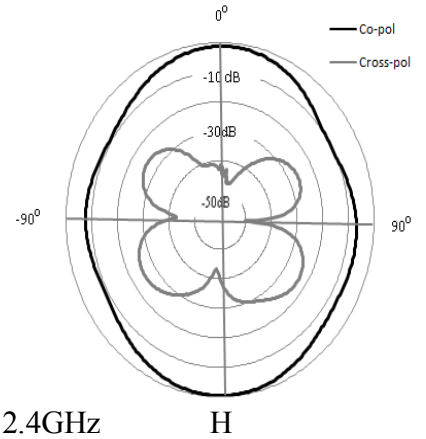

$2.4 \mathrm{GHz}$

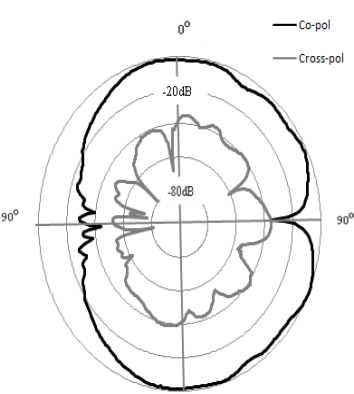

$\mathrm{E}$

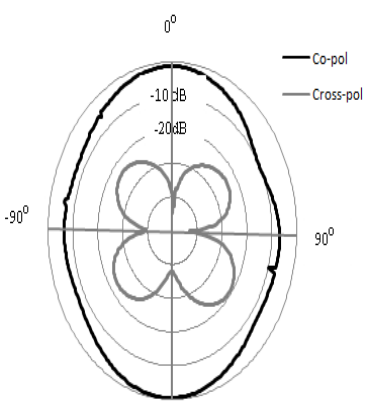

$\mathrm{H}$

Figure 5. Measured E-Plane and H-Plane Co-polarization and Cross-polarization patterns of Antenna 3 at different frequencies

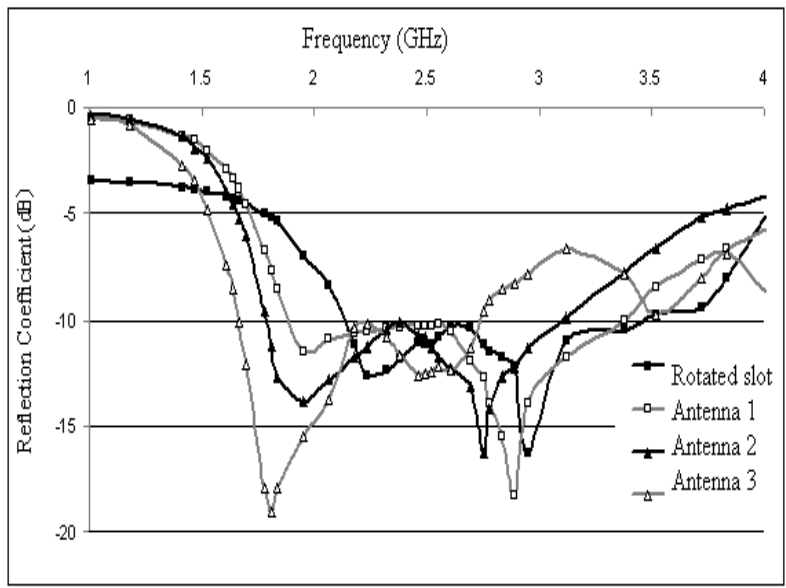

Figure 6. Measured reflection coefficients of the fractal slot antennas of three iterations.

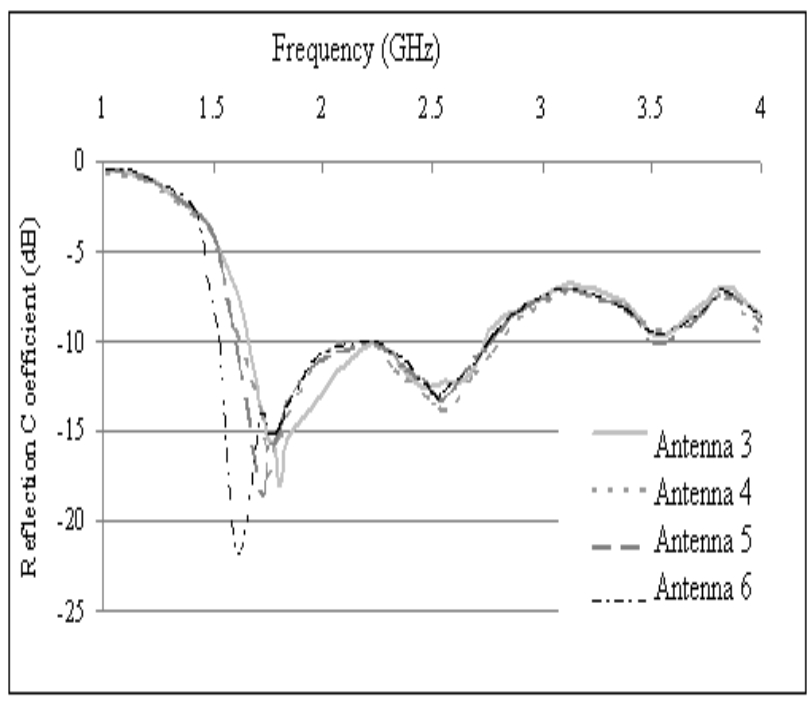

Figure 7. Measured reflection coefficients of the fractal slot antennas of iteration three with different IF and IA.

From the simulation results it can be inferred that Antenna1 with $\mathrm{IO}=1, \mathrm{IF}=0.35$ and $\mathrm{IA}=60^{\circ}$ gives more bandwidth (equal to $1550 \mathrm{MHz}$ ). From the Table 1 it is observed that while the IO increases the bandwidth decreases, resonance band is varying where the new lower band frequencies are added. Note that from the literature a printed slot antenna is a bi-directional radiator, so the measured $\mathrm{E}$ and $\mathrm{H}$ plane patterns are similar on both sides of the antenna. The performance of the proposed antenna is compared with reference antennas in Table 2.

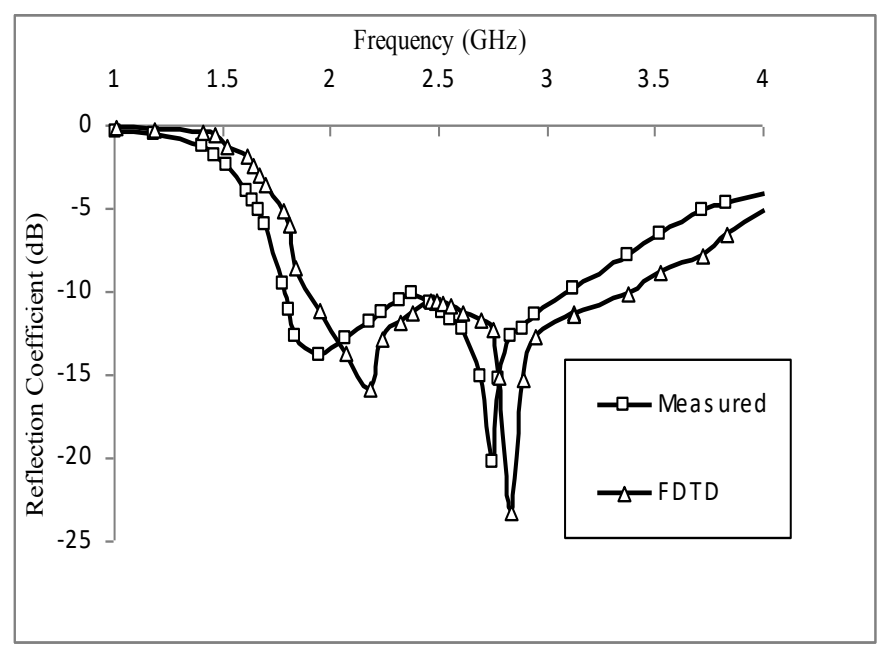

Figure 8. Comparison of Antenna $2(\mathrm{IO}=2)$ Reflection Coefficient.

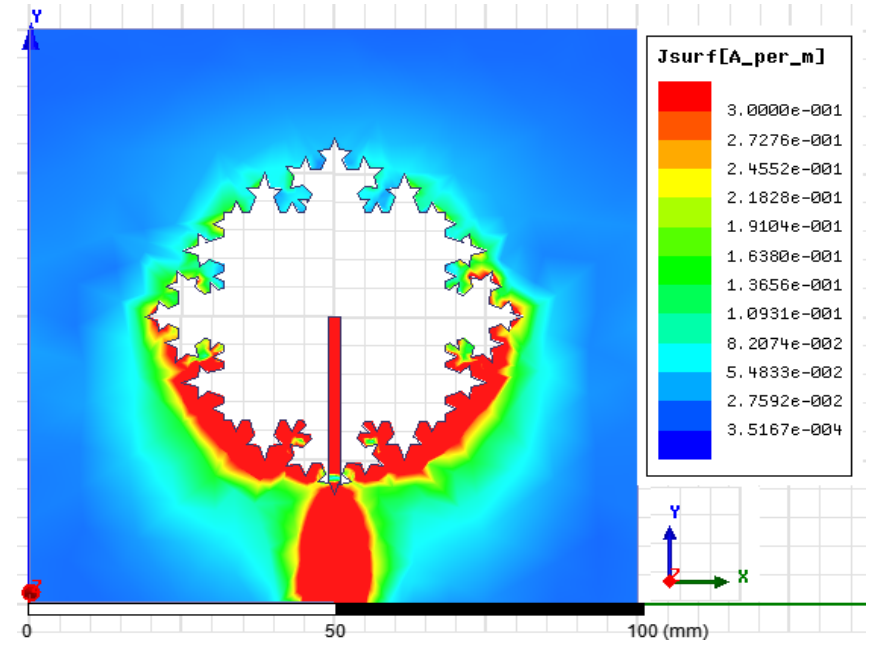

(a) $1.8 \mathrm{GHz}$ 


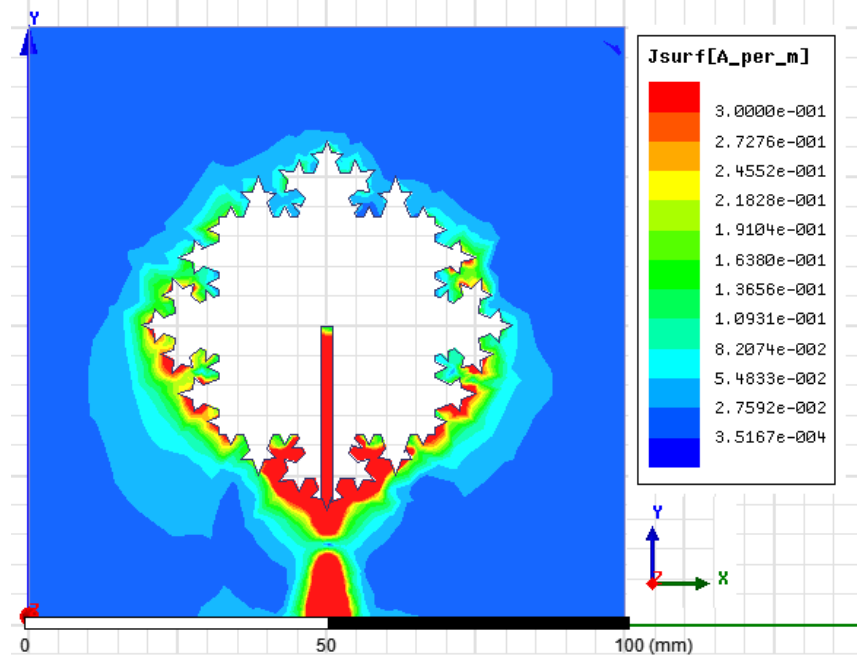

(b) at $3 \mathrm{GHz}$

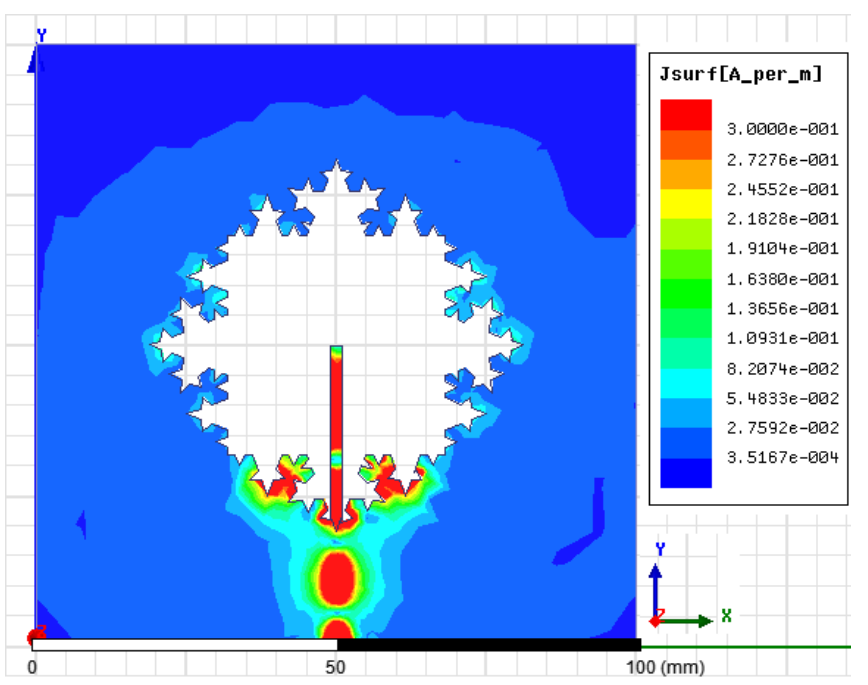

(c) at $4 \mathrm{GHz}$

Figure 9. The Electric current distribution of Antenna 3 at various frequencies.

Table 2: Comparison of the proposed antenna with reference antennas.

\begin{tabular}{|c|l|c|}
\hline Antenna & \multicolumn{1}{|c|}{ Description } & $\begin{array}{c}10 \text { dB return } \\
\text { loss Bandwidth } \\
(\%)\end{array}$ \\
\hline$[7]$ & Slot-Monopole Antenna & 51.2 \\
\hline$[8]$ & Rectangular slot & 54.16 \\
\hline$[15]$ & Fractal shaped slot & 44.5 \\
\hline$[17]$ & $\begin{array}{l}\text { Koch snowflake annular } \\
\text { slot-ring }\end{array}$ & 44.45 \\
\hline$[18]$ & Tree fractal based cross slot & 5.32 \\
\hline$[19]$ & Equilateral-triangular slot & 40.35 \\
\hline$[23]$ & Spidron Fractal Slot & 47.25 \\
\hline Proposed & $\begin{array}{l}\text { Koch fractal boundary } \\
\text { printed slot }\end{array}$ & 57.50 \\
\hline
\end{tabular}

\section{Conclusions}

A printed broad band square Koch fractal slot antenna has been investigated in this paper. Several fractal slot antennas are proposed by varying the IF, IA and IO. For every iteration order the IF and IA are optimized to get better bandwidth. It shows that with the increase of the IO, electrical length of the slot increases, which results lower frequency components become more dominant. The presented slot Antenna 1 generates the highest $10 \mathrm{~dB}$ return loss bandwidth which is about $57.5 \%$. Measured results are validated with the FDTD full wave analysis for Antenna 2. The proposed slot antennas are well suited for $2.4 \mathrm{GHz}$ ISM band wireless applications.

\section{Acknowledgements}

The authors thanks Antenna wing, DLRL-Hyderabad, for providing the measurement facilities.

\section{References}

K. L. Wong, Compact and Broadband Microstrip Antennas. New York: Wiley, 2002.

M. Kahrizi, T. K. Sarkar, and Z. A. Maricevic, Analysis of a wide radiating slot in the ground plane of a microstrip line, IEEE Transactions on Antenna and Propagations 41: 29-37, 1993.

J. Y. Sze, and K. L. Wong, Bandwidth enhancement of a microstrip line-fed printed wide-slot antenna, IEEE Transactions on Antenna and Propagations 49: 1020-1024, 2001.

Aliakbar Dastranj and Habibollah Abiri, Bandwidth Enhancement of Printed E-Shaped Slot Antennas Fed by CPW and Microstrip Line, IEEE Transactions on Antenna and Propagations 58: 1402-1407, 2010.

W. J. Lui, C. H. Cheng, and Y. Cheng, Frequency notched ultra-wideband microstrip slot antenna with a fractal tuning stub, Electronic Letters 41: 294-296, 2005.

Jen-Yea Jan and Jia-Wei Su, Bandwidth Enhancement of a Printed Wide-Slot Antenna With a Rotated Slot, IEEE Transactions on Antenna and Propagations 53: 2111-2114, 2005.

T. Kumar, and A. R. Harish, Broadband circularly polarized printed slot-monopole antenna, IEEE Antennas and Wireless Propagation letters 12: 1531-1534, 2013.

J. M. Chen, and Jeen-Sheen Row, Wideband circularly polarized slotted-patch antenna with a reflector, IEEE Antennas and Wireless Propagation letters 14: 575-578, 2015.

Y. J. Liao, and Hen-Lun Lin, Polarization Reconfigurable Eccentric Annular Ring Slot Antenna Design, IEEE Transactions on Antenna and Propagations 63: 4152-4155, 2015. 
C. K. Chang, Wen-Jiao Liao, and Chin-Che Tsai, Metal Body-Integrated Open-End Slot-Antenna Designs for Handset LTE Uses, IEEE Transactions on Antenna and Propagations 64: 5436-5440, 2016.

Constantine A. Balanis, Antenna Theory Analysis and Design, A John Wiley \& Sons, Inc., Publication.

C. Borja, and J. Romeu, On the behavior of the Koch island fractal boundary microstrip patch antenna, IEEE Transactions on Antenna and Propagations 51: 1281-1291, 2003.

W. L. Chen, G.-M.Wang, and C.-X. Zhang, Fractal-shaped switchedbeam antenna with reduced size and broadside beam, Electronic Letters 14: 1110-1111, 2008.

Steven R. Best, On the Performance Properties of the Koch Fractal and Other Bent Wire Monopoles, IEEE Transactions on Antenna and Propagations 51: 1292-1300, 2003.

W. L. Chen, Guang-Ming Wang, and Chen-Xin Zhang, Bandwidth Enhancement of a Microstrip-Line-Fed Printed Wide-Slot Antenna With a Fractal-Shaped Slot, IEEE Transactions on Antenna and Propagations 57: 2176-2179, 2009.

Y. J. Sung, Bandwidth Enhancement of a Wide Slot Using Fractal-Shaped Sierpinski, IEEE Transactions on Antenna and Propagations 59: 3076 - 3079, 2011.

M.T. Yassen, M.R. Hussan, H.A. Hammas, H. Al-Saedi, J.K. Ali, A compact dual-band slot antenna based on Koch fractal snowflake annular ring, Proceedings of Progress In Electromagnetics Research Symposium - Spring, PIERS, St. Petersburg; Russian Federation; 670-674, 2017.

A. R. Parvathy and M. Thomaskutty, A Printed Tree Fractal Based Cross Slot Antenna for $2.45 \mathrm{GHz}$, Procedia Computer Science 115: 80-86, 2017.

J. Wu, X. Ren, Z. Li, and Y. Z. Yin, Fractal-Based Triangular Slot Antennas with Broadband Circular Polarization for RFID Readers, Progress In Electromagnetics Research 51: 121-129, 2014.

M. O. Dwairi, M. S. Soliman, A. A. Alahmadi, I. I. A. Sulayman, and S. H. Almalki, Design regular fractal slotantennas for ultra-wideband applications, In Progress In Electromagnetics Research Symposium-Spring (PIERS), 3875-3880, 2017.

L. Ladhar, M. Zarouan, D. Oueslati, J. M. Floch, and H. Rmili, Investigation on cellular-automata irregular-fractal ultrawideband slot-antennas, Microwave and Optical Technology Letters 57:2506-2514, 2015.

A. Dastranj, and F. Bahmanzadeh, A Compact UWB Antenna Design Using Rounded Inverted L-Shaped Slots and Beveled Asymmetrical Patch, Progress In Electromagnetics Research 80: 131-140, 2018.

A. Altaf, Y. Yang, K. Y. Lee, K. C. Hwang, Wideband circularly polarized spidron fractal slot antenna with an embedded patch, International Jounral of Antennas and Propagtion, 1-7, 2017.

K. Ali, M. T. Yassen, M. R. Hussan and A. J. Salim, A printed fractal based slot antenna for multi-band wireless communication applications, Proceedings of Progress In Electromagnetics Research Symposium, Moscow, Russian Federation, 618-622, 2012.
Dennis M. Sullivan, electromagnetic Simulation using the FDTD method, IEEE press, New York, 2000. 